\title{
A POSIÇÃO DO TRANSEXUAL DIANTE DO PRINCÍPIO DA DIGNIDADE DA PESSOA HUMANA EM FACE DOS DIREITOS DA PERSONALIDADE: UMA LUTA PELA GARANTIA DE SUA REALIZAÇÃO E INCLUSÃO SOCIAL
}

\author{
THE POSITION OF TRANSEXUAL BEFORE THE PRINCIPLE OF HUMAN \\ DIGNITY IN FACE OF PERSONALITY RIGHTS: A FIGHT FOR \\ CONDUCTING YOUR WARRANTY AND SOCIAL INCLUSION
}

\author{
${ }^{1}$ Jossiani Augusta Honório Dias \\ ${ }^{2}$ José Sebastião de Oliveira
}

\section{RESUMO}

O ser humano nunca ocupou um espaço de tamanha relevância como nos tempos atuais. Os Direitos Humanos, nas suas mais variadas formas de manifestação, estão positivados por todo o mundo. Contudo, a situação dos transexuais ainda está à margem do direito, há uma resistência de aceitação da sociedade, movida pelo preconceito e pela dificuldade em aceitar as diferenças. $O$ texto pretende afastar alguns mitos e estigmas relativos aos transexuais, enfatizando a necessidade de reconhecimento e efetivação dos seus direitos ao caracterizá-los como direitos de personalidade, assim como ao associá-los à ideia de efetivação de um direito humano.

Palavras-chave: Transexual, Dignidade da pessoa humana, Direitos da personalidade

\section{ABSTRACT}

Human beings never occupied an area of such importance as in modern times . Human Rights , in its various manifestations, are positivized worldwide. However, the situation of transsexuals is still outside the law, there is an acceptance of resistance of society, moved by prejudice and difficulty accepting the differences. The text aims to dispel some myths and stigmas related to transsexuals, emphasizing the need for recognition and enforcement of their rights to characterize them as personal rights, and to associate them to the idea of realization of a human right.

Keywords: Transexual, Dignity of human person, Personality rights

\footnotetext{
${ }^{1}$ Pós Graduada em Direito Público Material pela Universidade Gama Filho -UGF, Piedade, Rio de Janeiro. Advogada pela DFD Contabí, (Brasil). Email: tutortreinamento@ gmail.com

2 Pós-Doutorado pela Universidade de Lisboa -UL, Lisboa, Portugal. Coordenador do Programa de Pós-graduação em Ciências Jurídicas pelo Centro Universitário de Maringá -UNICESUM AR, Maringá, Paraná, (Brasil).
} 


\section{INTRODUÇÃO}

No decorrer da história da humanidade, vivem-se incessantes transformações, o desafio está em manter a convergência do direito com os avanços sociais. Presencia-se um momento de multiplicidade e pluralidade social, entretanto, parte da sociedade tem resistência em aceitar as diferenças, logo, o que não se enquadra no padrão é percebido com incompreensão, discriminação e preconceito.

Dá-se conta que, ao longo dos tempos, houve muitas conquistas de homens e mulheres no sentido de ampliar e garantir direitos e liberdades, porém quando trata-se de sexualidade se depara com intensa dificuldade de se reconhecer a diversidade e o pluralismo. Há um aprisionamento em conceitos duais, homem/mulher, e tudo que foge à regra permanece à margem da sociedade, fomentado a vulnerabilidade desses grupos divergentes.

Em especial, apreciar-se-á a situação dos transexuais, seres que associam sua felicidade e satisfação a uma condição física diversa daquela com a que nasceram, em suma, nasceram com um sexo biológico com o qual não se identificam psicologicamente. A dimensão do problema está na sociedade que, repleta de discriminação e preconceito, obstrui a realização pessoal, profissional, afetiva desses indivíduos, lesionando os direitos da personalidade e a Dignidade humana deles, colocando-os à margem de uma vida social desigual.

É imprescindível reconhecer a diversidade sexual, de forma que assegurar a liberdade sexual implica em garantir a Dignidade da Pessoa Humana, já que o ser humano é dotado de racionalidade, e o ponto de partida de uma sociedade justa é a harmonia e satisfação do homem que, criado à imagem e semelhança de Deus, tem por fim a felicidade.

Ao passo que falar de Dignidade da pessoa humana, é tratar com seguridade da integridade física e psíquica do ser humano, implicando assim os Direitos da personalidade que devem ser garantidos universalmente a todos independentemente de suas diferenças.

Se o intuito é garantir ao homem um Estado Democrático de Direito, é inequívoco que a dignidade da pessoa humana deve ocupar um lugar central no pensamento filosófico, político e jurídico da sociedade. Nesse contexto, é incompreensível presenciar na atualidade situações que lesionam a integridade física e moral, e até mesmo aniquilam a própria vida, no Brasil existe uma certa omissão de leis que regulem e assegurem direitos para os transexuais, para sua realização como pessoa. O método empregado foi o teórico, utiliza-se bibliografia, textos, e documentos, com objetivo de conhecer, criticar, argumentar, através de uma abordagem documental, histórica e legislativa a real situação dos indivíduos transexuais. 
Emergencial que o direito forneça mecanismos que garantam ao transexual a adequação ao sexo que pertence, assegurando a redesignação e a retificação de sexo e nome do transexual em seus documentos, de forma a efetivar os direitos decorrentes do Direito da Personalidade, (vida, honra, imagem, nome e intimidade) inerentes à condição humana.

Neste esteio, repensar o ordenamento jurídico e se voltar às situações emergenciais parece essencial para preservação do sistema. Adequar e suprir as lacunas a fim de garantir a dignidade da pessoa humana, que é princípio vetor do nosso ordenamento jurídico, é tão emergencial quanto a necessidade de que a ordem jurídica possibilite que os transexuais tenham seus direitos personalíssimo garantidos.

\section{SEXUALIDADE HUMANA E O FENÔMENO DA TRANSEXUALIDADE}

Pode-se dizer que a sexualidade é inerente ao homem, desde os primórdios o sexo fez parte da realidade social. Patriarcalmente o conceito sexual se estabeleceu com a heterossexualidade e a reprodução humana, convencionando-se a relação de intimidade entre homem e mulher.

A trajetória histórica da sexualidade humana priorizou a legitimação da relação sexual como, antes de tudo, uma via de reprodução, especificamente na relação conjugal e fundamentada em rígidos pressupostos de 'moralidade', institucionalizando a virgindade, a heterossexualidade e resignação feminina como o modelo normal e padrão definidor da sexualid ade, humana.

Veemente que a sexualidade não é apenas algo biológico e com funções procriativas, abrange além dos aspectos biológicos, os psíquicos, os comportamentais, os civis e outros, que agregados determinam a sexualidade do indivíduo. De forma que a determinação sexual reflete na formação das teorias aplicáveis às ciências sociais, tais como o direito, que por sua vez tem o desígnio de acompanhar as evidentes mudanças das características das sexualidades ao longo do tempo, e tecer comandos jurídicos atuais e satisfatórios.

Para Michel Foucault, a sexualidade humana não é a mesma ao longo da história, não é algo sumamente natural e biológico, tecendo um conceito amplo e complexo, na obra História da sexualidade I, ensina:

A sexualidade é o nome que se pode dar a um dispositivo histórico: não à realidade subterrânea que se apreende com dificuldade, mas à grande rede da superfície em que a estimulação dos corpos, a intensificação dos prazeres, a incitação ao discurso, a formação dos conhecimentos, o reforço dos controles e das resistências, encadeiam-se uns aos outros, segundo algumas grandes estratégias de saber e de poder. (Foucault. 2011, p. 116-117). 
Percebe-se que conceituar sexualidade humana é uma tarefa complexa, devem ser tidos por base os processos históricos, o contexto histórico cultural, as crenças, as influências sociais, de forma a se criarem estruturas sexualmente fundamentadas e a se compreender que o sexo não se define por um simples aparelho genital, mais por um síncrono de elementos que identifica o indivíduo em termos de identidade, comportamento e realização social.

Nesse mesmo sentido, adverte Luiz Alberto David Araújo, que há muito o sexo deixou de estar relacionado somente à reprodução:

É certo que o assunto remete às origens da humanidade, mas, com o passar do tempo, temas como o amor, desejo, prazer, proteção ao patrimônio, acúmulo de bens, descendência sadia, controle populacional, sacralidade, culto à arte, entre outros, se destacaram, alterando e superando, ao longo da história, a ideia inicial de que o sexo está estritamente ligado à procriação. Pode-se dizer, inicialmente, que o sexo (e o que está relacionado à sexualidade) é algo que sempre acompanhou a realidade humana e social, especialmente quando se tem em vista a reprodução humana. Porém, com o passar do tempo, restou cada vez mais evidente a relação do sexo não somente com o aspecto reprodutivo, mas também os seus fortes reflexos nos campos da moral, da religião, da ciência, das artes e dos estados de ânimo associados ao prazer e ao amor . (ARAUJO, 2000, p.35-45).

Fácil constatar que tudo que se relaciona com sexo e sexualidade não pode ser reduzido a uma visão simplificada, porém a grande questão que envolve o tema é que a sociedade moderna continua a apregoar aos indivíduos, logo quando nascem, um status sexual homem/mulher, um conceito simplista baseado na anatomia, naturalmente dicotômico e mantido pela maioria dos sistemas legais conhecidos.

Salienta-se que os indivíduos que não se encaixam no contexto dual por vezes não têm seus direitos reconhecidos, tendo em vista que os comandos jurídicos atuais não exprimem as evidentes características de mudança na seara da sexualidade. Esbarra-se na resistência social, imbricada em dogmas, que não alcançam a diversidade, a fraternidade e o solidarismo social.

Ressaltando que a conceituação de sexo foge do dualismo homem-mulher, nos aponta Elimar Szaniawski quanto diversificada pode ser a sexualidade:

"A sexualidade do homem pode apresentar, não raras vezes, perturbações ou disfunções, denominadas, pela medicina, de anomalias sexuais. A anomalia sexual ou sexopatia é definida como o padrão de conduta sexual no qual os modos de realização do prazer sexual ocorrem através de formas distintas da relação heterossexual normal. As anomalias sexuais são classificadas, pela ciência, em intersexualismo, homossexualismo, transexualismo e travestismo". (SZANIAWSK, 1998, p.34).

É relevante ao Estado reconhecer os diferentes tipos de identidade sexual, considerando que o que define o sexo é uma série de fatores e não apenas o órgão genital, e no caso de 
discordância deve prevalecer o fator psicológico, por ser o elemento que integra o Estado da pessoa. O ser humano é dotado de racionalidade, é muito além que um corpo biológico.

Partidário dessa percepção preconiza Luiz Alberto David Araújo:

A busca da unidade é, portanto, o ponto mais importante da identificação sexual de um indivíduo. A identificação entre os diversos fatores caracterizadores da sexualidade é que determinará ser ou não uma situação revestida de normalidade. "Havendo desarmonia entre eles (os componentes para determinação do sexo), o componente que apresenta maior relevância é o psicológico". (ARAÚJO, 2000, p. 25).

Tratar-se-á em especial da situação do transexual, tendo em vista as consequências jurídicas que a mudança cirúrgica de sexo, e a busca para a adequação do nome implicam diretamente de respaldo na esfera jurídica.

Assinala-se que a transexualidade se revelou desde os primórdios dos tempos, porém a medicina e outros ramos só trataram do assunto nos últimos 50 a 70 anos. Imaginemos o conflito interior que vive um indivíduo que nasce com atributos físicos de um determinado sexo, mas pensa, sente e age como sendo do sexo oposto.

O jurista Elimar Szaniawsk (1998, P.58) constatou em seus estudos que a história do transexualismo é praticamente baseada em mitos e lendas, que revelam ter esta "síndrome" existido desde os primórdios da humanidade, embora o fenômeno somente tenha sido caracterizado como uma entidade médica, cientificamente analisada, há cerca de 50 anos.

Nos dias atuais, é muito comum se deparar com indivíduos transexuais, isso porque ao longo dos tempos eles foram conquistando espaço para terem o direito de se revelar, de se identificar. Pode-se afirmar que é uma conquista um tanto recente e que ainda existe uma busca para a efetiva inserção na sociedade, em especial no ordenamento jurídico, que via de regra, por inexistir legislações específicas, dispõe de decisões desencontradas, já que muitos juristas ainda consideram o sexo biológico o preponderante.

Não obstante, encontramos decisões que ressaltam a conceituação biológica em detrimento dos discursos da psicologia, da medicina e da antropologia, o que causa insegurança jurídica e um sistema deficiente que não ampara de forma efetiva os transexuais.

Importa trazer à baila o modo que a medicina se refere ao transexualismo: dispõe a Organização Mundial da Saúde (OMS) que o transexualismo está entre os Transtornos de Identidade Sexual (código F64.0) e pode ser descrito como um desejo de viver e ser aceito como um membro do sexo oposto, usualmente acompanhado por uma sensação de desconforto ou impropriedade de seu próprio sexo anatômico e um desejo de se submeter a tratamento hormonal e cirurgia para tornar seu corpo tão congruente quanto possível com o sexo preferido. 
Há muitos anos, esta classificação não é satisfatória, pois o que se reconhece é um transtorno de identidade sexual, e não uma identidade sexual diversa da considerada como normal, considerando-se uma patologia. Nesta linha de pensamento, mas tratando da homossexualidade, Freud, Jung e Adler, classificaram a homossexualidade como patologia, um distúrbio de personalidade psicopata. (FREUD, 1949)Com o advento dos movimentos gays, a partir dos anos 60, principalmente nos Estados Unidos, desenvolveu-se uma campanha para que a sociedade aceitasse os homossexuais como pessoas normais, entendendo serem eles portadores de preferência sexual diversa da dos heterossexuais.

Oportuno mencionar o psicólogo norte americano Robert Stoller (1982, p. 02), no livro "A Experiência Transexual", por exemplo, trata a transexualidade como uma manifestação médica quando indica que: Transexualismo é uma desordem pouco comum, na qual uma pessoa anatomicamente normal sente-se como membro do sexo oposto e, consequentemente, deseja trocar seu sexo, embora suficientemente consciente de seu verdadeiro sexo biológico.

Apontamos o entendimento de Maria Helena Diniz:

"Transexualidade é a condição sexual da pessoa que rejeita sua identidade
genética e a própria anatomia de seu gênero, identificando-se
psicologicamente com o gênero oposto. Trata-se de um drama jurídico-
existencial, por haver uma cisão entre a identidade sexual física e psíquica. Éa
inversão da identidade psicossocial, que leva a uma neurose reacional
obsessivo-compulsiva, manifestada pelo desejo de reversão sexual integral.
Constitui, por fim, uma síndrome caracterizada pelo fato de uma pessoa que
pertence, genotípica e fenotipicamente, a um determinado sexo ter consciência
de pertencer ao oposto. O transexual é portador de desvio psicológico
permanente de identidade sexual, com rejeição do fenótipo e tendência a
automutilação ou auto-extermínio. Sente que nasceu com o corpo errado, por
isso, recusa totalmente o seu sexo, identificando-se psicologicamente com o
oposto ao que lhe foi imputado na certidão de nascimento, apesar de
biologicamente não ser portador de qualquer anomalia". (DINIZ, 2002,
p.229).

A questão sobre a conceituação do transexual é pertinente e deve ser vista com cautela, já que a maneira que o judiciário irá interpretar é o modo com que fruirá dos direitos básicos, e a efetividade do princípio da Dignidade Humana aos transexuais. Assim, oportuna é a ponderação de Luiz Alberto David Araujo (2000, p.31), ao indicar que toda a busca pela integração do corpo, da mente e do espírito é no sentido de que a pessoa, que sofre com essas dificuldades, também possa integrar-se socialmente. O caminho, no entanto, é longo e árduo, e resultado de todo um processo de adequação, diverso de um "capricho passageiro".

Em síntese, transexualidade é um tema muito polêmico e, portanto, o que devemos ter em mente é que não se trata de promiscuidade, mas sim de pessoas que nasceram em um corpo que conflita com sua alma. Deste modo, o direito deve respeitar e densificar os meios de 
proteção aos direitos da personalidade desse grupo minoritário. Decisões divorciadas da realidade social humana, a dificuldade para tornar possível a adequação de sexo e a alteração de nome só implicam em mais sofrimento e discriminação, o que urgentemente deve cessar.

Posicionamentos massacrantes e discriminatórios, baseados no padronismo, afrontam até mesmo nossa Constituição Federal, que determina a ausência de discriminação e preconceito, ressaltando o princípio da dignidade da pessoa humana, os direitos fundamentais à liberdade individual e igualdade, cuidando para o bem de todos com o objetivo de alcançar uma sociedade justa e fraterna.

Oportuno aqui o ensinamento de Tereza Rodrigues Vieira (1998, p.357), que diz que "Culpar este indivíduo é o mesmo que culpar a bússola por apontar para o norte. A transexualidade, segundo nosso atual modo de pensar, é resultante de uma alteração genética no componente cerebral, combinado com alteração hormonal e o fator social. "

Imperante que o sistema jurídico determine a sexualidade, observando todo o contexto da pessoa, vida civil, relação com a sociedade, nome social e etc. A identificação de um indivíduo não pode mais se dar por um complexo de características físicas exteriores, sob pena de reprimir uma serie de direitos, lesionando a vida, a integridade física, a honra, a liberdade e outros direitos inerentes à pessoa humana.

Assim, concluímos que o transexual, como um ser igualmente portador de direitos e deveres, tem o direito de se adequar sexualmente tanto na esfera da saúde como legalmente, adequando seu nome e sexo, de maneira a reduzir seu sofrimento. Desta forma, o sistema jurídico estará em conformidade com os direitos e princípios previstos na Constituição Federal de 1988 e estarão ausentes a discriminação e o preconceito.

\section{PRINCÍPIO DA DIGNIDADE DA PESSOA HUMANA}

Em termos, a palavra dignidade vem do latim "digna", anunciando o que é merecedor, considerável, honroso, trata-se de um pressuposto de ideia do que é justo, considera o homem como um ser superior dotado de razão, sentimento, intrinsecamente ligado à dignidade. Versar sobre o Princípio da Dignidade Humana é resgatar atos predecessores à norma legislada, com valor transcendental, de modo que implica refletirmos a história da humanidade, onde a individualidade humana não passava de uma presunção.

Despontando na Grécia antiga, um homem chamado Ciro o Grande, conquistou a Babilônia, e revoltado pela não valorização humana decidiu valorizar a pessoa, concedendo 
liberdade a todos, inclusive aos escravos, sob o fundamento de que todos mereciam a liberdade e o valor. A ideia resplandeceu na Índia, Grécia, e Roma que, por sua vez, reconheceu que alguns direitos eram inerentes ao homem, criando a chamada Lei Natural. Porém, o poder ignorava seus preceitos e concedia direitos sob requisitos, como o nascimento com vida, formação física de ser humano etc, e ainda limitava esses direitos para os chefes de família, de forma que era monopolizado pelo Imperador e os pater familias, que detinham o poder de vida ou morte dos seus subordinados.

Neste diapasão, a Inglaterra também aderiu à ideia e é considerada a pátria da liberdade. Vários documentos importantes para proteger a dignidade humana procederam desse país, citemos a Magna Carta de 1215 do período do Rei João sem Terra, a petição de Direitos de 1628, a Lei do Habeas Corpus de 1679, e a Declaração dos Direitos de 1689, todos esses fazem parte da construção dos direitos fundamentais.

Em tal grau de importância, a França lutou arduamente para conquistar a liberdade e a igualdade. Os franceses diziam que seu direito não era inventado e sim natural, tornando assim o conceito trazido pelos romanos de Lei Natural por Direitos Naturais.

Historicamente visualizamos esse pensamento inclusive nas ideias do jusnaturalista de Emmanuel Kant, que afirmava ser o homem um fim em si mesmo, e por isso não pode ser tratado como objeto nem usado como meio de obtenção de qualquer objetivo.

Para o filósofo alemão:

"À ética tem por objeto a vontade do homem e prescreve leis destinadas a reger as ações humanas. A partir dessa ideia, surge o imperativo categórico, qual seja, "age de tal modo que a máxima de tua vontade possa se transformar em lei universal". Importante ressaltar que, para Kant, "quando uma coisa tem um preço, pode pôr-se em vez dela qualquer outra equivalente; mas quando uma coisa está acima de todo o preço e, portanto, não permite equivalente, então tem ela dignidade". Tal pensamento culmina num segundo enunciado do imperativo categórico: "toda pessoa, todo ser racional, existe como um fim em si mesmo e não como meio para o uso arbitrário da força". (KANT, 2007. p. 33).

A Revolução Francesa marcou o início dos primeiros direitos do homem e a influência do movimento iluminista consolidou os direitos fundamentais da pessoa, mas, somente no século XX, diante das atrocidades da Segunda Guerra Mundial, é que o princípio da Dignidade da Pessoa Humana ganhou força, inclusive publicou-se a Carta das Nações Unidas elaborada durante a Segunda Guerra Mundial.

Diante da necessidade da sua normatização, em 1945, cinquenta e um países assinaram 
a carta de fundação da ONU e, em 1948, foi aprovada a Declaração Universal dos Direitos Humanos, que estabeleceu direitos e garantias aos direitos mais elementares da pessoa, fazendo referência à dignidade humana em seu art. $1^{\mathrm{o}}$ : "todos os seres humanos nascem livres e iguais em dignidade e em direitos. Dotados de razão e de consciência, devem agir uns para com os outros em espírito e fraternidade".

É mister destacar que esses direitos evoluíram conforme o desenvolvimento da sociedade, pelo que são classificados por geração, ou dimensão. A primeira geração/dimensão estabeleceu a liberdade negativa por parte do Estado, constituiu direitos civis e políticos. A segunda restabeleceu a forma participativa do Estado, que passa a agir positivamente, garantindo os direitos culturais, econômicos e sociais, econômicos, foi o período do liberalismo, e a intervenção do Estado. A terceira geração ou dimensão marcou os direitos de solidariedade e fraternidade, contemplou a proteção do meio ambiente, bem como assegurou o direito ao desenvolvimento e proteção do gênero humano. A quarta geração tutelou as minorias deferindo direitos. A quinta dimensão ou geração foi marcada pelo avanço tecnológico e pesquisa da biomedicina, retratando os direitos decorrentes desses fenômenos e podendo ser chamada de “dimensão dos direitos fundamentais".

Diante de toda essa construção histórica, o princípio da dignidade da pessoa humana passou a ser o valor fundante e nuclear do ordenamento jurídico, de forma que o ser humano é dotado de prevalência, e garantir a integridade e liberdade da pessoa humana é fator determinante do Direito.

Referindo ao valor dispensado à pessoa humana, Luís Roberto Barroso (2011, p.680), dispõe sobre a necessidade de se garantir um mínimo de integridade à pessoa natural em razão de sua existência humana, almejando explicitar o respeito obrigatório a condições materiais mínimas de existência, integridade física e valores morais e espirituais, evitando-se, portanto, a "coisificação" da pessoa e propiciando a valorização do ser em relação ao ter.

O Estado deve garantir os direitos fundamentais, viabilizar a concretização da dignidade humana, assegurando a liberdade e igualdade, não permitindo discriminações e preconceitos, promovendo tratamento desigual aos desiguais e igualitário aos iguais.

Precisamente, a ordem jurídica está em torno do Princípio da dignidade humana, se existe um problema jurídico a solução é pensar o que será mais coerente e digno ao ser humano, de forma que deve-se analisar também o centro do sistema jurídico, nossa Constituição Federal, ressaltando-se sempre a importância de reconhecer a plena realização e até mesmo a felicidade do homem, no meio social onde vive. 
No Brasil, um país democrático, o princípio da dignidade da pessoa humana foi consagrado e ganhou força normativa e coercitiva, tendo sido estabelecido como fundamento do Estado Democrático de Direito no artigo $1^{\circ}$, inciso III, da Constituição da República de 1988: Art. $1^{\circ}$. A República Federativa do Brasil, formada pela união indissolúvel dos Estados e Municípios e do Distrito Federal, constitui-se em Estado Democrático de Direito e tem como fundamentos: [...] III - a dignidade da pessoa humana; [...].

Ressalta-se a importância da Constituição Federal Brasileira, pois trata-se de um documento pluralista que respeita acima de tudo o ser humano, permeia todo o ordenamento jurídico como ordem suprema, consagra princípios que comprometem o Brasil até mesmo na ordem internacional, requer acima de tudo uma sociedade justa e solidária com a prevalência dos direitos humanos.

Nesse sentido leciona Luís Roberto Barroso:

Nesse ambiente, a Constituição passa a ser não apenas um sistema em sicom a sua ordem, unidade e harmonia -, mas também um modo de olhar e interpretar todos os demais ramos do direito. Este fenômeno, identificado por alguns autores como filtragem constitucional, consiste em que toda a ordem jurídica deve ser lida e apreendida sob a lente da Constituição de modo a realizar os valores nela consagrados. Como antes já assinalado, a constitucionalização do direito infraconstitucional não tem como sua principal marca a inclusão da Lei Maior de normas próprias de outros domínios". (BARROSO, 2009, p.35).

Inequívoco que a Dignidade da Pessoa humana registrada em nossa Constituição Federal de 1988 restou em concretizar os direitos fundamentais do homem, de forma que tamanha abrangência torna difícil conceituar com exatidão o que realmente expressa a essência desse princípio. Ingo Sarlet a conceitua como:

Qualidade intrínseca e distintiva reconhecida em cada ser humano que o faz merecedor do mesmo respeito e consideração por parte do Estado e da comunidade, implicando neste sentido, um comple xo de dire itos e deveres fundame ntais que assegure m à pe s soa tanto contra todo e qualquer ato de cunho degradante e desumano, como venham a the garantir as condições existenciais mínimas para uma vida saudável, além de propiciar e promover sua participação ativa e corresponsável nos destinos da própria existência e da vida em comunhão com demais elementos humanos. (SARLET, 2010, p.60).

Notório que o valor supremo da ordem jurídica é garantir a Dignidade Humana a todos, considerando cada um na sua individualidade, materializando sua personalidade, viabilizando a felicidade e satisfação do homem, elementos básicos para sua realização e desenvolvimento.

Desta feita, preconiza Luiz Alberto Araújo:

É de importância vital (na expressão mais real da palavra) que o indivíduo 
viva bem consigo mesmo e, consequentemente, com os outros; não ocorrendo isso, não há possibilidade de ser feliz. Felicidade é um sentimento abstrato, mas básico e essencial para qualquer realização. Ser ou estar feliz é perceberse com pessoa, ser humano, poder criar, amar e contribuir com o meio em que se vive, integrar-se dentro de seus limites pessoais. (ARAUJO, 2000. p. 45).

Suscitamos ser essencial que a partir desse entendimento da dignidade como palavra de ordem, cabe refletir a situação da pessoa transexual e analisar sob esse prisma se existem barreiras para a formação da personalidade, abarcando os aspectos funcionais de adequação sexual, do nome e sexo, as condições morais e sociais que são oferecidas ao homem na condição de transexual, perante o meio social em que nasce, cresce, e se desenvolve culturalmente.

Inquestionável a necessidade de se concretizar por meio da atuação do Estado Democrático de Direito a realização pessoal do transexual, por intermédio de mecanismos imediatos que possam garantir e tutelar os direitos de personalidade e a dignidade humana desses indivíduos, superando-se o sectarismo social, e fazendo valer a precípua missão estatal de preservar o sistema sob pena de ter-se um Estado vazio em seus propósitos.

\section{DIREITO À IDENTIDADE SEXUAL DIVERSA}

A propósito, é muito conveniente e pertinente relacionar o Princípio da Dignidade Humana com o direito à identidade sexual diversa, já que um autêntico Estado Democrático de Direito deve reconhecer, respeitar e garantir não só o estado sexual, mas o estado da pessoa individualmente considerada, garantindo uma plena representação e realização.

É mister que o Estado da pessoa é composto de vários elementos, como a saúde, a idade, o sexo e outros que têm por função representar a pessoa no meio social, porém a teoria jurídica não avista todas as situações da existencialidade, reprimindo diversos aspectos sociais concretos. Tomamos como exemplo os transexuais, que vivem o constrangimento de ter a aparência característica de um sexo e ser identificado, através da análise de seus documentos, como pertencente ao sexo oposto.

A identidade sexual é muito peculiar e individual, porém é a maneira como o indivíduo se representa socialmente. Muito categórico Alexandre Oliveira conceitua:

Aquilo que denominamos identidade sexual nada mais é do que o direito de ser internamente e aparecer externamente igual a si mesmo com a realidade do próprio sexo. Por outro lado, a autodeterminação sexual do indivíduo, neste contexto, é a formulação jurídica da construção da identidade sexual, que se norteará pela liberdade, sobretudo a espiritual, como a de sentir, de pensar, de 
decidir, de criar, de consciência, de agir e omitir, como veremos na segunda parte deste trabalho. Ora, esta liberdade tem por escopo a busca da felicidade, que é o objetivo de todo o ser humano em sua jornada por este mundo. (OLIVEIRA, 2003, p. 68).

O Estado Democrático e Social de Direito tem o dever de reconhecer a liberdade de identidade sexual e manter-se pluralista, reconhecendo diversas formas de viver e de relacionarse, porém muitas vezes as formas rígidas de comportamento acabam por excluir e censurar diversas situações.

Nesse sentindo Farina preceitua:

"Há diversos tipos de estigma, e em todos podemos, de alguma forma, identificar a situação do transexual, por exemplo a estigmatização decorrente das deformidades do corpo. Exsurgem, também, as denominadas culpas de ordem individual, tais como, por exemplo, "os distúrbios mentais, prisão, vício, alcoolismo, homossexualismo, desemprego, tentativas de suicídio e comportamento político radical". Há, ainda, os estigmas referentes à raça, religião e nação, mas em todos, se encontra a mesma característica, qual seja, "um indivíduo que poderia ter sido facilmente recebido na relação social quotidiana possui um traço que pode se impor à atenção e afastar aqueles que encontra, destruindo a possibilidade de atenção para outros atributos seus". (FARINA, 1982 p. 14).

Em geral se tratando de termos evolutivos da espécie humana, é necessário que o indivíduo, qualquer seja, não sofra restrições da sua vontade individual. A identidade sexual é um elemento de representação importantíssimo e está atrelada aos direitos da personalidade, à saúde, à liberdade, à vida social etc. É deveras importante reconhecer a angústia do transexuais, que não possuem um sexo harmônico e seu maior desejo é enquadrar-se como homens ou mulheres, de forma que exprimem seu estado sexual diariamente nos seus relacionamentos e práticas cotidianas de sua vida. Assim, deve-se reconhecê-los e integrá-los na sociedade, como quaisquer outros cidadãos comuns

Como se disse, os transexuais são dotados de um sexo, porém se identificam como o oposto, sofrem de uma incompatibilidade entre sexo biológico e sua verdadeira identidade sexual, que the proporciona um incontrolável anseio de reversão sexual, sentindo muitas vezes repudio da genitália com que vieram ao mundo. Se considerarmos que o sexo é definido por um conjunto de fatores, compreenderemos que isso pode naturalmente acontecer. A jurista Tereza Viera (1998, p.109), também entende que se o conceito e o entendimento de sexo não estão relacionados somente ao conjunto de caracteres físicos e genéticos, mas também psicológicos, que se agregam aos primeiros

A despeito do assunto sexualidade e cultura, preconiza Habermas, na sua obra Lutas pelo reconhecimento no estado democrático constitucional: 
A classificação dos papéis sexuais e das diferenças dependentes do gênero toca fundamentalmente os níveis do auto-entendimento cultural de uma sociedade. Assim, ser homem ou mulher, sentir-se feminino ou masculino faz parte da estrutura de compreensão da própria cultura de uma dada sociedade . (HABERMAS, 1998, p. 133).

Mormente que a sociedade e o ordenamento jurídico brasileiro tenham evoluído bastante, e a Constituição Federal do Brasil atendendo a realidade brasileira optou pelo pluralismo, em geral o preconceito em aceitar a situação dos transexuais como fato normal é muito marcante no meio social. Tratar de diferenças como a do transexual é despertar preconceitos e discriminações, de forma a ferir a dignidade humana desses indivíduos, que clamam por igualdade, liberdade, justiça e fraternidade. Neste sentido José Afonso Da Silva (1999, p.56), afirma que a Constituição optou pela sociedade pluralista, que respeita a pessoa humana e sua liberdade, em lugar de uma sociedade monista, que mutila os seres e engendra as ortodoxias opressivas, dividindo os seres humanos apenas entre homens e mulheres.

Oportuno mencionarmos os ensinamentos de Luiz Araujo:

O Estado perde a centralidade normativa a respeito do assunto pois há necessidades humanas de habitar o próprio corpo vivenciando o sexo/gênero construído ao longo da/em vida e do viver. Os conflitos e consensos vão dando razão às novas maneiras de enxergar o status sexual. Havendo, assim, modificações das tradições, outrora bem marcadas. Aquelas crenças, contudo, acabam por justificar e estimular práticas preconceituosas e até perversas direcionadas a estes indivíduos que não se submetem às clássicas desigualdades entre homens e mulheres, supostamente baseadas em diferenças físicas e biológicas. Tal contexto, obviamente, dificulta sobremaneira a sua inserção nos grupos sociais. (ARAUJO, 2000, p. 53).

Denota-se a liberdade de identificação sexual como elemento de representação social, em geral, deve-se garantir liberdade aos membros de uma sociedade, principalmente quando tratamos de direitos fundamentais e personalíssimos. A pretensão de adequação do nome, do gênero do transexual, seu direito de realizar ou não a cirurgia, bem como o tratamento hormonal, devem ser garantidos e concretizados pelo poder público, tendo em vista a função do Estado de tutelar os direitos individuais e de personalidade.

Uma situação comum ao transexual é o anseio de adequar o nome e o sexo no registro civil, pois, na falta da legislação específica, convive muitas vezes, até mesmo depois da cirurgia e da adequação visual, o transtorno de continuar por um bom tempo sendo tratado por nome diverso do social. $\mathrm{O}$ civilismo tradicional prega a imutabilidade do nome, entretanto o que deve prevalecer é o direito de personalidade e dignidade da pessoa, concretizando sua realidade sexual e se representando como tal na sociedade. 
A situação é tão vexatória, e constrangedora que o doutrinador do tema Elimar Szaniawski (1998, p. 116), afirmou ser constrangedor ter a aparência característica de um sexo e ser identificado, através da análise de seus documentos, como pertencente ao sexo contrário. Tal constatação, no entender, é a mais tormentosa das situações, para uma pessoa humana.

Neste caminho de pensamento, observa-se que, por meios criteriosos, tem-se permitido a alteração do nome e sexo ao transexual. Mesmo diante de divergentes decisões, o que prevalece é a mudança plena, inclusive garantindo o direito ao esquecimento na medida que estabelece não ser necessário constar a situação sexual anterior no seu documento civil.

Acerca da cirurgia para a mudança de sexo, mesmo sem legislação especifica, é concedida pela rede pública de saúde. Depois de muita resistência do judiciário, inclusive de tratar a cirurgia como lesão corporal e mutilação, o sistema jurídico respeita e impõe ao poder público o dever da realização desse procedimento, haja vista que esse processo promove a adequação física à psíquica, sendo um tratamento importante para a saúde do transexual e para a realização pessoal dessa pessoa.

Depois de muitas questões médicas e jurídicas, chegou-se à conclusão de que a cirurgia em questão nada mais é do que um tratamento de saúde. Segundo Farina, os transexuais sentemse melhor, sexual e psicologicamente, após a realização da cirurgia de conversão sexual, desaparecendo a ansiedade e a depressão eventualmente presentes antes do procedimento cirúrgico. (FARINA, P. 250).

Em razão de todo exposto, vê-se que analisar o ser Humano a partir de sua configuração corporal ou física é negar sua condição de digno. Afirma-se isto porque são a racionalidade e a autonomia que thes conferem o lócus especial na escala dos seres, a racionalidade e autonomia que o tornam digno. Assim, quando o Ser Humano é visto e identificado a partir do seu corpo anatômico, e não da mente, é apenas mais um animal que, embora racional, é visto pelo sistema sem se considerar esta variável, que é de fundamental importância. O exercício do direito à identidade deve ser exercido de modo a valorar o sistema jurídico, satisfazendo as necessidades sociais e desempenhando o espírito agregador do nosso ordenamento jurídico.

Nesse contexto, pode-se afirmar que o direito de sexualidade diversa é marcado por inúmeros desafios, dos quais, muitos violam o Princípio da Dignidade da Pessoa Humana. Limitar e até mesmo não conceder esse direito baseando-se em dogmas e valores lineares é não reconhecer o avanço social que o direito e a medicina já atingiram a respeito da transexualidade e difundir o preconceito. 
Propício se refletir sobre solidariedade, fraternidade e igualdade, que são os objetivos do sistema jurídico, pois vive-se em um Estado laico, plural, sendo fundamental não disseminar o preconceito e a exclusão, e sim intentar uma sociedade livre, justa, solidária, de forma que garantir a adequação de sexo e o direito de identidade do transexual é medida que traduz proteção aos elementos fundamentais da personalidade do ser humano, quais sejam, a dignidade, a indivisibilidade e a pessoalidade.

\section{DIREITOS DA PERSONALIDADE DOS TRANSEXUAIS}

Os direitos da personalidade, em geral, foram positivados pela primeira vez na Lei Romena de 1895, posteriormente, em 1900, o Código Alemão assegurou o direito ao nome, e, em 1907, o Código Suíço conferiu a necessidade de preservação do nome, zelando como atributo da personalidade humana. Um novo relevo dos direitos da personalidade se deu com o Código Civil Italiano de 1948, que disciplinou outros aspectos da personalidade, elencando o direito ao próprio corpo, direito ao pseudônimo, direito à imagem, além de assegurar o direito ao nome.

Trançando outros desdobramentos, o Código Civil Português de 1966, tutelou especificamente tais direitos em capítulo próprio, da mesma forma fez o nosso atual Código Civil Brasileiro, de 2002. Apesar de previamente assegurados na nossa Constituição de 1988, a positivação dos direitos da personalidade em ordenamento infraconstitucional, no ano de 2002, reforçou e assegurou mais força normativa a esse instituto, tão importante e tão necessário no arcabouço das garantias pessoais.

Ressalta-se que o arcabouço relativo ao direito de personalidade não é recente, há muito já existia a preocupação de assegurar os direitos fundamentais de cada pessoa, tratando-se de direitos que se desenvolveram aos fundamentos da valorização da pessoa humana.

Retratar integralmente os direitos da personalidade é tarefa árdua, tendo em vista a diversidade da contextualização humana. Compreende-se serem algumas condições indispensáveis ao ser humano, como o direito à vida, ao nome, a honra, a imagem, a intimidade, a liberdade de expressão, entre outros, que inequivocamente integram direitos fundamentais do ser humano. 
É mister que alguns direitos prevaleçam sobre outros, visando garantir os direitos para a formação da personalidade, que é essencial para que se possa usufruir das demais garantias do ordenamento. Nesse sentindo Orlando Gomes conceitua Direitos da Personalidade da seguinte forma:

São direitos essenciais ao desenvolvimento da pessoa humana, que a doutrina moderna preconiza e disciplina, no corpo do Código Civil, como direitos absolutos. Destinam-se a resguardar a eminente dignidade da pessoa humana, preservando-a dos atentados que pode sofrer por parte de outros indivíduos. Ou, por fim, como define Francisco Amaral, "direitos da personalidade são direitos subjetivos que têm por objeto os bens e valores essenciais da pessoa, no seu aspecto físico, moral e intelectual"(GOMES, 2001, p. 243).

Em verdade, os direitos da personalidade resguardam direitos subjetivos e inerentes ao homem, asseguram um mínimo comum que reconhece à pessoa dignidade e projeção social, são veiculados a todos que a partir do nascimento com vida, passam a ser sujeitos de direitos e deveres. Não é possível delimitar com precisão os direitos da personalidade, deve-se observar o contexto histórico, a condição humana, a particularidade de cada um, enfim a diversidade da realidade da vida humana, de uma pessoa no meio social.

Manifesta-se que os direitos da personalidade visam assegurar a integridade física e moral do ser humano, independentemente de cor, credo, etc, ressalta-se a importância do direito à identidade, ou seja, o direito de ser visto como realmente se é, o que está incorporado aos direitos da personalidade e deve ser conferido a todos sem qualquer distinção. Não obstante aqui se tratar da situação dos transexuais, que nitidamente sofrem a aniquilação de se identificarem como tal, por vezes lutam para ter integração e reconhecimento social, constatando-se uma real divergência do sistema jurídico e a consagração de fato na realidade jurídico-social quando trata-se da diversidade sexual.

Observa-se que, no caso dos transexuais, a recusa do reconhecimento se dá pelo simples fato de o indivíduo não se identificar com o sexo biológico do seu corpo anatômico, objetivando uma identidade sexual diversa da atribuída no seu nascimento. Ressalta-se que conceder o direito de alteração de nome e sexo no registro civil é imperante para o pleno desenvolvimento da personalidade do indivíduo, e para o transexual é muito mais marcante esse direito.

Neste seguimento, leciona Roxana Borges:

Os humanos têm direitos ao pertencimento e modificação do próprio corpo. O corpo das pessoas é um aparelho do viver ganho com o início da vida - ainda dentro do útero materno. Além dos direitos imediatos, como a tutela a respeito da integridade física, há os direitos mediatos, entre os quais estão situados os 
direitos de autogerir a própria vida em referência ao corpo, viver os diversos aspectos das sexualidades quanto a si mesmo livremente, reflexos do direito à disposição corporal. Portanto, entre os direitos circunscritos à autonomia corporal está o direito à própria singular sexualidade - utilizar e vivenciar como melhor the aprouver -, com todos os seus tons atuais . (BORGES 2007, p. 168).

Se considerarmos que a época atual impõe a Dignidade como condutora de todo ordenamento jurídico, é inexorável a importância do homem, um ser que encerra um fim em si mesmo, de forma que destituir seus direitos ou coisifica-ló, negando o direito de uma nova identidade, é ofender a personalidade humana, e segregar as minorias, ligadas aos grupos vulneráveis.

Óbvio que o sistema jurídico não estabelece discriminações, no entanto a sociedade enclausurada a valores éticos e morais ultrapassados, vinculados ainda a padrões das civilizações greco-romanas, externa preconceito e discriminação aos transexuais. A maior angústia desses indivíduos nos dias atuais, sem dúvida, não é mais a busca para a readequação genital, pois esse é um objetivo conquistado, mas sim a busca para o equilibrio social, alterando o nome e sexo no registro civil, que não é tarefa fácil na justiça brasileira, onde cada magistrado, cada tribunal superior expressa entendimento distinto, contribuindo para decisões divergentes ${ }^{3}$.

A supressão desses direitos decorre da falta de uma legislação específica que ampare a vulnerabilidade dos transexuais, por exemplo, as leis atuais deixam em aberto a questão do registro civil dos transexuais. Os indivíduos se deparam, com a lentidão processual, e ainda com decisões controvertidas, o que acarreta insegurança jurídica e muitas vezes desvirtua e denigre a pessoa do transexual perante a sociedade, causando-lhe constrangimentos, ferindo, sem qualquer dúvida, seus direitos de personalidade.

Neste contexto preconiza ANTÔNIO CHAVES:

Lamentavelmente nossas leis, costumes, tradições não têm um mínimo de compreensão, tolerância e consideração para aqueles que a natureza ou a vida criou uma situação esdrúxula, paradoxal, dissonante quanto à perfeição de sua sexualidade, condenando-os inexoravelmente a uma vida miserável dentro do mais aviltante dos ostracismos . (CHAVES, RT, 1986).

Assinalem-se muitos posicionamentos doutrinários em relação ao tema, porém o mais sensato e coerente é obedecer aos parâmetros da Constituição Federal de 1988 e conceder a alteração do nome e sexo no registro civil, garantindo o direito a imagem e liberdade aos

\footnotetext{
${ }_{3}^{3}$ Espn $^{\circ} 1.008 .398$-SP, a relatora Ministra Nancy Andrighi aduziu: O transexual que tenha se submetido à cirurgia de mudança de sexo pode trocar nome e gênero emregistro sem que conste anotação no documento. A decisão,inédita, foi da Terceira Turma, em outubro de 2009. O colegiado determinou, ainda, que o registro de que a designação do sexo foi alterada judicialmente conste apenas nos livros cartorários, sem constar essa informação na certidão (REsp 1.008.398).
} 
transexuais. É certo que conceder o direito ao nome condizente com o gênero sexual, regulamentar os procedimentos necessários à conformação do sexo, é cumprir o espírito da dignidade da pessoa humana e garantir a efetividade dos Direitos Personalíssimos da classe de indivíduos transexuais. Imperativo se faz que o Legislativo se pronuncie e regulamente o direito à alteração de nome e redesignação sexual para que os transexuais não convivam por tanto tempo com atos irracionais de preconceito, sempre sujeitos a decisões judiciais divergentes e conquiste sem tardar a sua Dignidade.

Do que se expôs, tutelar os direitos da personalidade dos transexuais é a forma como autêntico Estado Democrático de Direito deve proceder, cabendo a ele aferir soluções de urgência para resguardar aos transexuais os direitos à identidade, à privacidade, à vida, à honra, dentre outros que possam garantir seu desenvolvimento pessoal no seio da sociedade brasileira.

\section{CONCLUSÃO}

Nos mais diversos percursos da vida, o ser humano almeja o reconhecimento pleno. Com o transexual, esse sentimento é mais intenso, pois tão cedo não se reconhece no seu sexo biológico e luta para a adequação do sexo de nascimento ao seu sexo psicológico, que é de outra natureza. $\mathrm{O}$ acolhimento por parte da sociedade supera em muito a necessidade das mudanças cirúrgicas e jurídicas. Fundamental a compreensão de como é e se expressa ser, para que não seja nomeado sempre de transexual, mas sim permitindo que conquiste sua identidade de ser homem ou mulher, enfim de ser um ser humano nos padrões habituais da sociedade.

Vimos que, não obstante, um ordenamento jurídico que prepondera o homem e que tem por objetivo a dignidade da pessoa humana, existem limites jurídicos que mantêm o judiciário impassível da real situação dos transexuais, ancorados em concepções excessivamente estreitas e impermeáveis às perspectivas que efetivamente dão realmente Dignidade Humana às suas vidas em sociedade, sendo um verdadeiro dilema até que consigam conquistar sua real identidade sexual.

É realmente angustiante a vida do transexual, que luta por direitos mínimos e ainda sofre repulsa da sociedade, the impondo na vida cotidiana restrições e preconceitos, de modo que é medida de urgência o Estado garantir a dignidade desse cidadão através da criação de legislação especial que possa de maneira mais branda e efetiva, assegurar a adequação sexual em todos os seus aspectos. 
Até o presente momento, esses anseios dos transexuais somente são possíveis por intermédio do acesso à justiça, em processos complexos e morosos, quando na realidade o mais adequado e digno, é torná-los mais simples, extrajudicialmente.

\section{REFERÊNCIAS}

ARAUJO, Luiz Alberto David. A proteção constitucional do transexual. São Paulo: Saraiva, 2000 .

BARROSO, Luis Roberto. Diferentes, mas iguais: o reconhecimento jurídico das relações homoafetivas no Brasil. Revista Brasileira de Direito Constitucional (RBDC): Revista do Programa de Pós-Graduação Lato Sensu . São Paulo: ESDC, 2011.

BARROSO, Luís Roberto. O novo direito constitucional e a constitucionalização do direito. 2009.

BORGES, Roxana Cardoso Brasileiro. Direitos de personalidade e autonomia privada. 2. ed. São Paulo: Saraiva, 2007.

BRASIL. Constituição da República Federativa do Brasil de 1988. Disponível em: <http://www.planalto.gov.br/ccivil_03/constituicao/Constituicao.htm>. Acesso em: 05 jan. 2016.

CHAVES, Antônio. Direito à vida e ao próprio corpo. $2^{\mathrm{a}}$ ed. revista e ampliada. São Paulo: Revista dos Tribunais, 1986.

DINIZ, Maria Helena. O estado atual do biodireito. 2. ed. aum. ed. atual. de acordo com o novo Código Civil (Lei 10.406, de 10-01-2002). São Paulo: Saraiva, 2002.

FARINA, Roberto. Transexualismo: do homem à mulher normal através dos estados de intersexualidade e das parafilias. São Paulo: Novolunar, 1982.

FREUD, Sigmund. Três ensaios sobre a teoria da sexualidade e outros trabalhos. Tradução James Strachey. Londres: Imago Publishing Co, 1949. v. VII.

FOUCAULT, Michel história da sexualidade 1: A vontade de saber. Rio de Janeiro: Graal, 2011.

GOMES, Orlando. Introdução ao Direito Civil. 18. ed. Rio de Janeiro: Forense, 2001. 
HABERMAS, Jürgen. Lutas pelo reconhecimento no estado democrático constitucional. Tradução Marta Machado. In: TAYLOR, Charles (Org.). Multiculturalismo. Lisboa: Instituto Piaget, 1998.

KANT, Immanuel. Fundamentação da metafísica dos costumes. Tradução de Paulo Quintela. Lisboa: Edições 70, 2007.

Luiz Alberto David. A proteção constitucional do transexual. São Paulo: Saraiva, 2000.

OLIVEIRA, Alexandre Miceli Alcântara de. Direito de autodeterminação sexual: dignidade, liberdade, felicidade e tolerância. São Paulo: Editora Juarez de Oliveira, 2003.

OMS. CID-11. Versão beta. Disponível http://apps.who.int/classifications/icd11/browse/lm/en>. Acesso em: 04 jan. 2016.

ONU. Declaração universal dos direitos do homem. Disponível em: $<$ http://www.humanrights.com/pt/what-are-human-rights/universal-declaration-ofhumanrights/articles-01-10.html>. Acesso em: $1^{\circ}$ de fev. 2016.

SARLET, Ingo Wolfgang. Dignidade da pessoa humana e direitos fundamentais na Constituição de 1988. Porto Alegre: Livraria do Advogado, 2010.

SILVA, José Afonso da. Aplicabilidade das normas Constitucionais. 3. ed. São Paulo: Malheiros 1999.

STOLLER, Robert J. A experiência transexual. Tradução Imago Editora. Rio de Janeiro: Imago, 1982. (Coleção: Psicologia psicanalítica)

SZANIAWSKI, Elimar. Direitos de personalidade e sua tutela. 2. ed. Rev., atual. e ampl. São Paulo: Revista dos Tribunais, 2005.

SZANIAWSKI, Elimar. Limites e possibilidades do direito de redesignação do estado sexual: estudo sobre o transexualismo aspectos médico e jurídicos. São Paulo: Revista dos Tribunais, 1998.

VIEIRA, Tereza Rodrigues. Natureza jurídica do direito à mudança de sexo e os direitos da personalidade, IOB 3/14731, 1998. 